Revue bibliographique pour le domaine irano-aryen

\title{
Klaus Vondrovec. Coinage of the Iranian Huns and their Successors from Bactria to Gandhara (4th to 8th century CE)
}

\section{Rika Gyselen}

\author{
(2) OpenEdition \\ Journals \\ Édition électronique \\ URL : http://journals.openedition.org/abstractairanica/42634 \\ DOI : 10.4000/abstractairanica.42634 \\ ISBN : 1961-960X \\ ISSN : 1961-960X \\ Éditeur : \\ CNRS (UMR 7528 Mondes iraniens et indiens), Éditions de l'IFRI
}

Référence électronique

Rika Gyselen, « Klaus Vondrovec. Coinage of the Iranian Huns and their Successors from Bactria to Gandhara (4th to 8th century CE) », Abstracta Iranica [En ligne], Volume 37-38-39 | 2018, document 9, mis en ligne le 22 mars 2018, consulté le 28 septembre 2020. URL : http://journals.openedition.org/ abstractairanica/42634; DOI : https://doi.org/10.4000/abstractairanica.42634

Ce document a été généré automatiquement le 28 septembre 2020

Tous droits réservés 


\title{
Klaus Vondrovec. Coinage of the Iranian Huns and their Successors from Bactria to Gandhara (4th to 8th century CE)
}

\author{
Rika Gyselen
}

\section{RÉFÉRENCE}

Klaus Vondrovec. Coinage of the Iranian Huns and their Successors from Bactria to Gandhara (4th to 8th century CE) [Studies in the Aman ur Rahman Collection, volume 4], Wien : Verlag der Österreichischen Akademie der Wissenschaften, 2014, 960 p. (2 vol.). ISBN 978-3-7001-7695-4

1 Jusqu'à l'apparition de ces deux volumes, Dokumente zur Geschichte der Iranischen Hunnen in Baktrien und Indien publié par R. Göbl en 1967 était resté l'ouvrage de référence pour l'histoire et la numismatique de la Bactriane et du Gandhara. Avec une documentation qui représente aujourd'hui cinq fois plus de monnaies que dans les années 1960, une révision s'imposait. L'ouvrage de K.V. s'inscrit dans ce projet.

2 L'objectif de ce travail est de fournir une vue aussi vaste et complète que possible de la documentation numismatique disponible actuellement. S'y associe le souhait de reconstituer l'histoire de la Bactriane et du Gandhara à une époque largement contemporaine de la dynastie sassanide (224-650 AD), puis de l'époque omeyyade. La nature même de ces monnayages - peu portent une date ou un lieu d'émission - ainsi que celle de leurs émetteurs - des chefs de tribus qui ne restent pas nécessairement au même endroit - rend l'image numismatique de ces nombreuses frappes très complexe. C'est dire que l'établissement d'une séquence chronologique (et géographique) de ces divers monnayages ne peut découler que d'une étude stylistique très stricte et précise, et de quelques repères fournis par le monnayage sassanide. 
3 La tâche de présenter ces divers monnayages d'une manière claire et compréhensible était ardue. En dix chapitres l'auteur réussit à fournir pour le monnayage de dix groupes (Kidarites, Alkhan, Hephtalites, etc.) une étude stylistique très détaillée accompagnée d'un catalogue des monnaies; chaque chapitre comporte en outre une présentation des autres sources disponibles et une ébauche de l'histoire du groupe qui est l'émetteur des monnaies concernées.

4 L'ouvrage est très richement illustré avec beaucoup de dessins et d'agrandissements photographiques des monnaies, malheureusement souvent reproduits de façon trop sombre.

5 Un onzième chapitre donne un aperçu typologique de ces divers monnayages permettant d'identifier une monnaie rapidement. On trouve dans le douzième chapitre un glossaire numismatique, la liste des noms géographiques, une carte générale de la région, une liste des monnaies présentant des particularités techniques, différents index dont un des contremarques, des tamgas et symboles, ainsi que les références bibliographiques.

6 Un travail exemplaire et indispensable pour comprendre cette époque si mouvementée à l'est de l'Iran.

\section{AUTEURS}

\section{RIKA GYSELEN}

CNRS, Mondes iranien et indien 